\title{
Dipole Glass in Chromium-Substituted Bismuth Pyrostannate
}

\author{
S.S. Aplesnin ${ }^{1,2}$, L.V. Udod ${ }^{1,2}$, M.N. Sitnikov ${ }^{2}$, V.V. Kretinin ${ }^{2}$, M.S. Molokeev ${ }^{1}$, N. Mironova- \\ Ulmane $^{3}$
}

${ }^{1}$ Kirensky Institute of Physics, Federal Research Center KSC SB RAS, Krasnoyarsk, 660036 Russia

${ }^{2}$ Reshetnev Siberian State University of Science and Technology 660037, Krasnoyarsk, Russia

${ }^{3}$ Institute of Solid State Physics, LV-1063 Riga, Latvia

\begin{abstract}
To establish the existence of dipole glass in the chromium-substituted bismuth pyrostannate solid solutions, the frequency and temperature dependences of the permittivity have been measured in the temperature range of 300-750 K. The field and dynamic dependences of polarization in the temperature range of $80-550 \mathrm{~K}$ have been determined. Using the Raman scattering spectra, the absence of inversion center has been established. The maximum of electrical resistance has been found in the vicinity of the dipole moment freezing point. The carrier type has been determined from the thermopower data. The polarization relaxation is shown to be nonexponential. The experimental data are explained within the model of dipole glass in the $\alpha$ - phase and the model of charged crystalline domain walls with the electronpolarization relaxation mechanism above the $\alpha-\beta$ structural transition.
\end{abstract}

\section{Introduction}

Multicomponent bismuth stannates, which belong to the pyrochlore and layered perovskite structural types, attract much attention of researchers as materials for theoretical and experimental investigations and are promising for application in designing novel electronic devices and new-generation storage systems. For instance, bismuth titanates with the layered perovskite structure are ferroelectrics with the high Curie temperatures, which exhibit the ferroelectric properties in a wide temperature range and can be applied in radio-, acousto- and optoelectronics, in particular, in fabricating radio capacitors, piezoelectric converters, filters, and pyroelectric infrared sensors [1,2]. In view of possible use of bismuth stannates as multiferroic and spintronic materials, substitution of magnetic ions for $3 \mathrm{~d}$ metals in these compounds has been intensively investigated. Bismuth-containing niobates with a pyrochlore-type structure are used as a hardware components for microelectronics devices [3].

The search for compounds with the strong correlation of the magnetic and electrical properties is of great practical and fundamental importance. The interaction of the ion subsystem with the electron subsystem characterized by the spin and orbital magnetic moment underlies the diversity of physical properties.

Bismuth pyrostannate $\mathrm{Bi}_{2} \mathrm{Sn}_{2} \mathrm{O}_{7}$ belongs to the pyrochlore family and its chemical formula can be written as $\mathrm{Bi}_{2} \mathrm{Sn}_{2} \mathrm{O}_{6} \mathrm{O}^{\prime}$. The $\mathrm{Bi}_{4} \mathrm{O}^{\prime}$ tetrahedra in the $\mathrm{Bi}_{2} \mathrm{Sn}_{2} \mathrm{O}_{6} \mathrm{O}^{\prime} \alpha$-phase tend to arrange bismuth ions in disordered rings around the ideal position with certain preference for ordering between neighboring bismuth atoms [4]. The average displacements of bismuth ions from the ring center and perpendicular to the ring are 0.044 and $0.008 \mathrm{~nm}$, respectively. The $\mathrm{Bi}_{2} \mathrm{Sn}_{2} \mathrm{O}_{7} \alpha$-phase structure is interpreted as monoclinic. The energy of the monoclinic structure calculated using the model proposed in [5] is lower than the body-centered trigonal structure 
energy by $0.2 \mathrm{eV}$. The $5 \mathrm{~d}^{10} 6 \mathrm{~s}^{2} 6 \mathrm{p}^{0}$ electronic configuration of a bismuth ion contains an unshared s electron pair. The structural distortion leads to the electron density asymmetry on the bismuth ion and induces the dipole moment, according to the electron density of states calculated by the LDA method with regard to the gradient correction of the exchange-correlation functional [6]. The unshared pair causes the high mobility of bismuth and oxygen atoms in the $\mathrm{Bi}_{4} \mathrm{O}^{\prime}$ sublattice and their strong displacements from the centers of positions characteristic of the ideal pyrochlore structure [6]. Oxygen ions have two types of environment and can be surrounded by bismuth ions or by tin and bismuth ions. Substitution of different-valence ions give rise to the shift of oxygen ions and enhancement of the dipole moment.

The pyrochlore compounds with magnetic ions, e.g., $\mathrm{Yb}_{2} \mathrm{Ti}_{2} \mathrm{O}_{7}$ [7] and $\mathrm{A}_{2} \mathrm{Sn}_{2} \mathrm{O}_{7}(\mathrm{~A}=\mathrm{Ho}$, Dy) stannates [8], belong to the highly frustrated systems with the short-range magnetic order and spin-ice state $[9,10]$. Current interest in spin ices has been stimulated by investigations of their dynamics, which are generally agreed to be controlled by the emergence of magnetic monopole excitations, the first example of a fractional quasiparticle in a three-dimensional magnet [11]. At the transition to the spin ice state, the diffuse scattering of polarized neutrons sharply grows. The pyrochlore compounds containing nonmagnetic ions with an unshared electron pair can also be considered as dielectric ice [12], whose dielectric behavior is explained by local hoppings of atoms in the A and O' positions between several potential minima [13]. This means, in fact, that the domains permanently change. Since the $\mathrm{O}^{\prime}$ ion can occupy both positions, the domains will order at short distances (e.g., in $\mathrm{Bi}_{2} \mathrm{Ti}_{2} \mathrm{O}_{7}[5]$ ).

In the $\mathrm{Bi}_{2} \mathrm{Ti}_{2} \mathrm{O}_{6} \mathrm{O}^{\prime}$ pyrochlore, the correlated displacements of bismuth around the ideal position lead to the formation of a short-range order with the averaged cubic structure [5]. This offers a sharp contrast to the $\mathrm{Bi}^{3+}$-containing $\mathrm{BiMnO}_{3}$ and $\mathrm{BiFeO}_{3}$ perovskites, where the "active unshared pair" in the A position causes the polar non-cubic ground states [5].

Thus, bismuth ions are shifted from the ring center along the Bi-O' bond and, in addition, in the ring plane and have six degenerate states. These displacements lead to the occurrence of polar states. In bismuth titanates, the dipole moments form glass.

Substitution of tin ions to $\mathrm{Cr}^{3+}$ ions in $\mathrm{Bi}_{2} \mathrm{Sn}_{2} \mathrm{O}_{7}$ should remove the six-fold degeneracy of the dipole moment as result of the shift of bismuth to the chromium cation, which can increase the polarization. Heterovalent substitution can induce the electron polarization. The dielectric and ferroelectric properties of bismuth pyrostannate substituted by magnetoactive ions have been understudied. According to the structural and theoretical investigations, a dipole glass can form in the cubic pyrochlore structure as a result of freezing of the dipole moments of the unshared bismuth-oxygen electron pair. The change in the local symmetry of the structure upon cation substitution will enhance the effect.

The aim of this work was to establish the correspondence of the model to the dielectric states in chromium-doped bismuth pyrostannate $\mathrm{Bi}_{2}\left(\mathrm{Sn}_{1-\mathrm{x}} \mathrm{Cr}_{\mathrm{x}}\right)_{2} \mathrm{O}_{7}(\mathrm{x}=0.05$ and 0.1$)$ and determine the correlated states of dipole moments of the dipole glass type.

\section{Experimental}

\subsection{Sample preparation and $X$-ray reflectivity measurements}

The $\mathrm{Bi}_{2}\left(\mathrm{Sn}_{1-\mathrm{x}} \mathrm{Cr}_{\mathrm{x}}\right)_{2} \mathrm{O}_{7}$ sample was synthesized by the solid-phase reaction according to the scheme

$$
2(1-\mathrm{x}) \mathrm{SnO}_{2}+2 \mathrm{xCr}_{2} \mathrm{O}_{3}+\mathrm{Bi}_{2} \mathrm{O}_{3} \rightarrow \mathrm{Bi}_{2}\left(\mathrm{Sn}_{1-\mathrm{x}} \mathrm{Cr}_{\mathrm{x}}\right)_{2} \mathrm{O}_{7}
$$


where $\mathrm{x}=0.05$ or 0.1 . The initial materials were $\mathrm{Bi}_{2} \mathrm{O}_{3}, \mathrm{SnO}_{2}$, and $\mathrm{Cr}_{2} \mathrm{O}_{3}$ oxides of the extra-pure grade. The initial oxide mixture was tableted, placed in an oven, and kept at temperatures from 700 to $950^{\circ} \mathrm{C}$ for $8-24 \mathrm{~h}$.

The crystal structure of $\mathrm{Bi}_{2} \mathrm{Sn}_{2} \mathrm{O}_{7}$ at room temperature is a distorted pyrochlore structure [14] and undergoes three polymorphic transitions $[15,16]$. The $\alpha$ - phase of $\mathrm{Bi}_{2} \mathrm{Sn}_{2} \mathrm{O}_{7}$ has to a monoclinic space group $P 1 c 1 \quad(\beta=90.04)$ without inversion center, 176 crystallographically independent atoms and thermodynamically stable up to $137^{\circ} \mathrm{C}$ [17]. The unit cell contains 32 $\mathrm{Bi}^{3+}$ ions, $32 \mathrm{Sn}^{4+}$ ions, and $112 \mathrm{O}^{2-}$ ions (Fig. 1). All $\mathrm{Bi}^{3+}$ ions are surrounded by eight oxygen ions and form a distorted cube; $\mathrm{Sn}^{4+}$ ions are surrounded by six oxygen ions forming distorted octahedral which interconnected by common vertices. Each atom is displaced from the corresponding position of the ideal pyrochlore cubic structure; the Sn-O sublattice is distorted much less than the $\mathrm{Bi}-\mathrm{O}^{\prime}$ one.

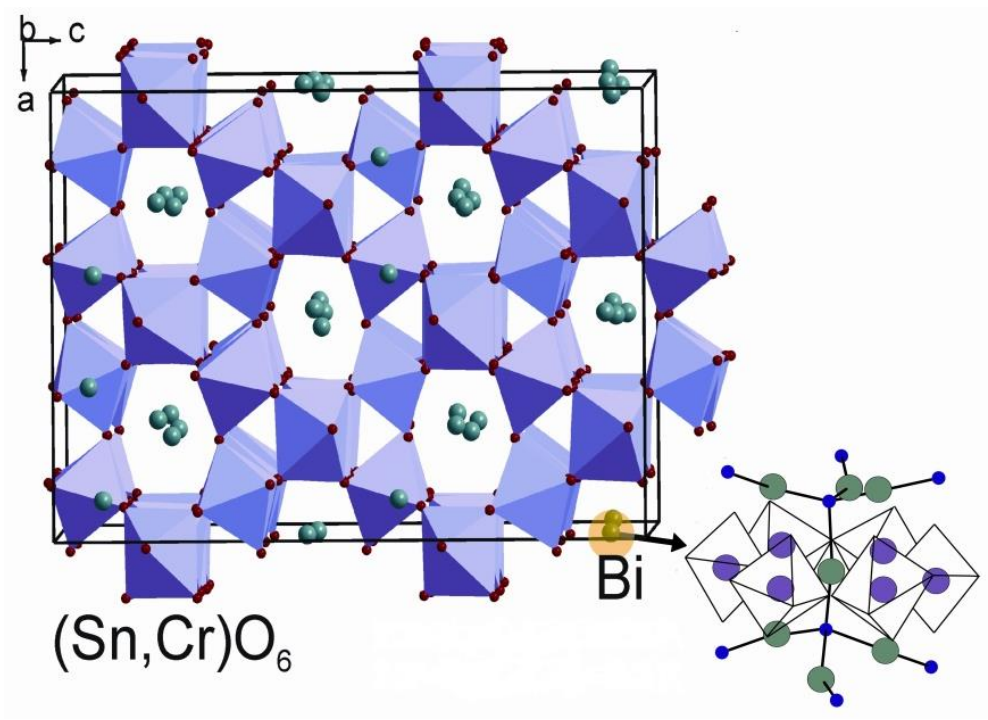

Figure 1 Crystal structure of $\mathrm{Bi}_{2} \mathrm{Sn}_{2} \mathrm{O}_{7}$. The $\mathrm{BiO}_{8}$ fragment is shown separately, in the centre of octahedral is $\mathrm{Sn}$. Color code: $\mathrm{O}$ atoms are at the corners of the blue octahedral, $\mathrm{O}$ ' in dark blue.

The average displacements from the ideal pyrochlore structure are $0.389,0.104,0.189$, and $0.312 \AA$ for $\mathrm{Bi}, \mathrm{Sn}, \mathrm{O}$, and $\mathrm{O}^{\prime}$, respectively. Sn atoms have a valence of +4 and the $4 \mathrm{~d}^{10} 5 \mathrm{~s}^{0}$ electronic configuration; $\mathrm{Bi}$ atoms acquire the +3 valence and have the $5 \mathrm{~d}^{10} 6 \mathrm{~s}^{2}$ electronic configuration. The $\beta$-phase structure determined by neutron and synchrotron $\mathrm{X}$-ray diffraction is trigonal (sp. gr. $F 43 c\left(T_{d}^{5}\right)$ ) [4]. The transition $\alpha \rightarrow \beta$ at $135^{\circ} \mathrm{C}$ is accompanied by the second harmonic generation [18]. Above $680^{\circ} \mathrm{C}$, there is one more polymorphic transition to the $\gamma$ phase (sp. gr. $F d 3 m$ ) [18-20].

The synthesized $\mathrm{Bi}_{2}\left(\mathrm{Sn}_{1-\mathrm{x}} \mathrm{Cr}_{\mathrm{x}}\right)_{2} \mathrm{O}_{7}, \mathrm{x}=0.05$ and 0.1 samples were studied on a Bruker D8 ADVANCE X-ray diffractometer with a VANTEC linear detector $\left(\mathrm{CuK}_{\alpha}\right.$ radiation) at room temperature (Fig. 2a). All the peaks on the X-ray diffraction pattern, except for two weak impurity peaks of unknown phase, correspond to the monoclinic $P c$ cell in the $\mathrm{Bi}_{2} \mathrm{Sn}_{2} \mathrm{O}_{7} \alpha$ - phase [17]. The Rietveld refinement was performed using the TOPAS 4.2 program [21]. The coordinates of all 176 atoms were fixed and borrowed from [17], since the number of only the coordinates 528 is comparable with the number of observed reflections. Nevertheless, even the fixed atomic coordinates allowed us to correctly describe all the available reflections and the refinement yielded low unreliability factors (see Table 1 and Fig. 2a). A linear decrease in the 
unit cell volume with increasing substitute concentration (Fig. 2b) is indicative of the singlephase nature of the $\mathrm{Bi}_{2}\left(\mathrm{Sn}_{1-\mathrm{x}} \mathrm{Cr}_{\mathrm{x}}\right)_{2} \mathrm{O}_{7}$ compositions, since the ionic radius $\mathrm{IR}\left(\mathrm{Cr}^{3+}, \mathrm{CN}=6\right)=$ $0.615 \AA$ is smaller than the ionic radius $\mathrm{IR}\left(\mathrm{Sn}^{4+}, \mathrm{CN}=6\right)=0.69 \AA$ [22]. $\mathrm{Cr}^{+3}$ ions occupy mainly the octahedral positions.
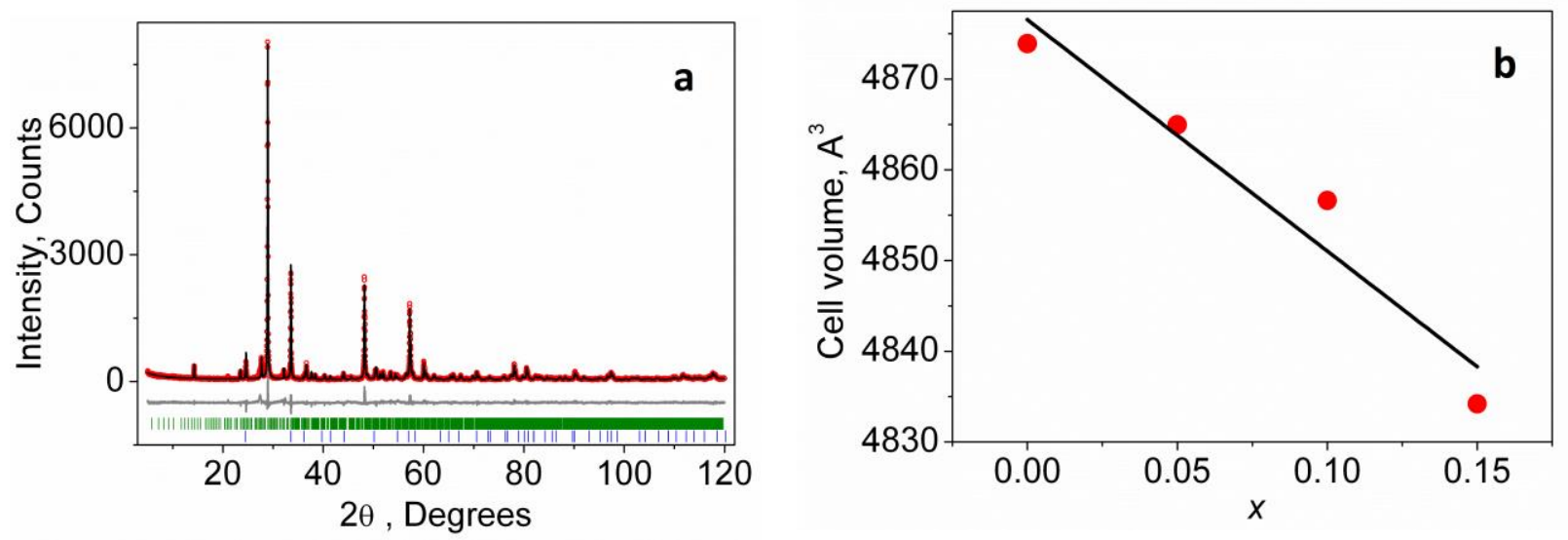

Figure 2 (a) Difference XRD pattern of $\mathrm{Bi}_{2}\left(\mathrm{Sn}_{1-\mathrm{x}} \mathrm{Cr}_{\mathrm{x}}\right)_{2} \mathrm{O}_{7}$. The upper curve shows the experimental XRD pattern; the middle curve, the theoretical XRD pattern; and the lower curve, the difference between the theoretical and experimental XRD patterns. (b) Cell parameters of

$$
\mathrm{Bi}_{2}\left(\mathrm{Sn}_{1-\mathrm{x}} \mathrm{Cr}_{\mathrm{x}}\right)_{2} \mathrm{O}_{7}
$$

Table 1. Main experimental parameters and refined data for the $\mathrm{Bi}_{2}\left(\mathrm{Sn}_{1-\mathrm{x}} \mathrm{Cr}_{\mathrm{x}}\right)_{2} \mathrm{O}_{7}$

\begin{tabular}{|c|c|c|}
\hline$x$ & 0.05 & 0.1 \\
\hline Sp. gr & $P c$ & $P c$ \\
\hline$a, \AA$ & $15.0634(13)$ & $15.075(1)$ \\
\hline$b, \AA$ & $15.1055(12)$ & $15.0823(1)$ \\
\hline $\mathrm{C}, \AA$ & $21.381(2)$ & $21.3589(13)$ \\
\hline$\beta,^{\circ}$ & $89.924(7)$ & $89.905(4)$ \\
\hline$V, \AA$ & $4865.0(7)$ & $4856(5)$ \\
\hline $2 \theta$ interval, ${ }^{\circ}$ & $5-90$ & $5-90$ \\
\hline$R_{w p}, \%$ & 13.93 & 13.62 \\
\hline$R_{p}, \%$ & 10.21 & 10.06 \\
\hline$R_{B}, \%$ & 5.08 & 5.56 \\
\hline $\mathrm{X}^{2}$ & 1.75 & 1.7 \\
\hline
\end{tabular}

The capacitance and dissipation factor were measured on an AM-3028 component analyzer in the frequency range of $0.1-1000 \mathrm{kHz}$ at temperatures of $100-750 \mathrm{~K}$. The charge and electrical resistance were determined on a Keithley $6517 \mathrm{~b}$ electrometer in the temperature range of 300-750 K. Microwave Raman spectra were recorded in the backscattering geometry at room temperature through a 50x microscope objective using a Renishaw inVia micro-Raman spectrometer equipped with an argon laser $(514.5 \mathrm{~nm}$, maximum power is $10 \mathrm{MW})$. The spectral signal was scattered by a 2400 -grooves $/ \mathrm{mm}$ diffraction grating to a Peltier-cooled CCD detector with a resolution of $1 \mathrm{~cm}^{-1}$. Field dependences of the electric polarization of $\mathrm{Bi}_{2}\left(\mathrm{Sn}_{1-\mathrm{x}} \mathrm{Cr}_{\mathrm{x}}\right)_{2} \mathrm{O}_{7}$ were investigated by a quasi-static method at frequencies of 10,3 , and $1 \mathrm{mHz}$ in the temperature range of $80-550 \mathrm{~K}$. Two measurement cycles were performed on the samples with silver 
contacts; the contacts were separated from the sample by a lacquer spacer to prevent leakage currents.

\subsection{Permittivity}

The spectral and temperature dependences of the permittivity can be used to detect the electric dipole moment and establish its characteristics, even when a local dipole moment exists in small clusters. In addition, the dielectric properties give information about the charge transport and charge ordering processes.

The temperature dependence of the $\mathrm{Bi}_{2}\left(\mathrm{Sn}_{1-\mathrm{x}} \mathrm{Cr}_{\mathrm{x}}\right)_{2} \mathrm{O}_{7}(\mathrm{x}=0.05$ and 0.1$)$ permittivity at several frequencies is shown in Fig. 3. In the $\alpha$-phase for the composition with $x=0.05$, the permittivity weakly depends on frequency and temperature. As the concentration of chromium ions increases in the temperature range of (370-560) $\mathrm{K}$, additional anomalies in the form of broad dielectric loss maxima arise, the temperature of which increases logarithmically with the frequency. The temperature dependence of the frequency is exponential: $\omega=\omega_{0} \operatorname{epx}(-\Delta \mathrm{E} / \mathrm{kT})$ with activation energy of $\Delta \mathrm{E}=0.4 \mathrm{eV}$, where $\mathrm{k}$ is the Boltzmann constant. According to the relation $\omega \tau=1$, the dipole moment relaxation time obeys the Arrhenius law $\tau=\tau_{0}$ epx $(\Delta \mathrm{E} / \mathrm{kT})$, which describes the relaxation in disordered systems. When tin is replaced with chromium, bismuth ions are displaced from the ring center and form the electric dipole moments. In the glass state, the dipoles are randomly distributed in a rigid isotropic matrix and the system has no polarization. This state is not paraelectric either: each dipole remembers its original orientation. Upon approaching the temperature of the phase transition $\beta \rightarrow \gamma$, the permittivity sharply grows.
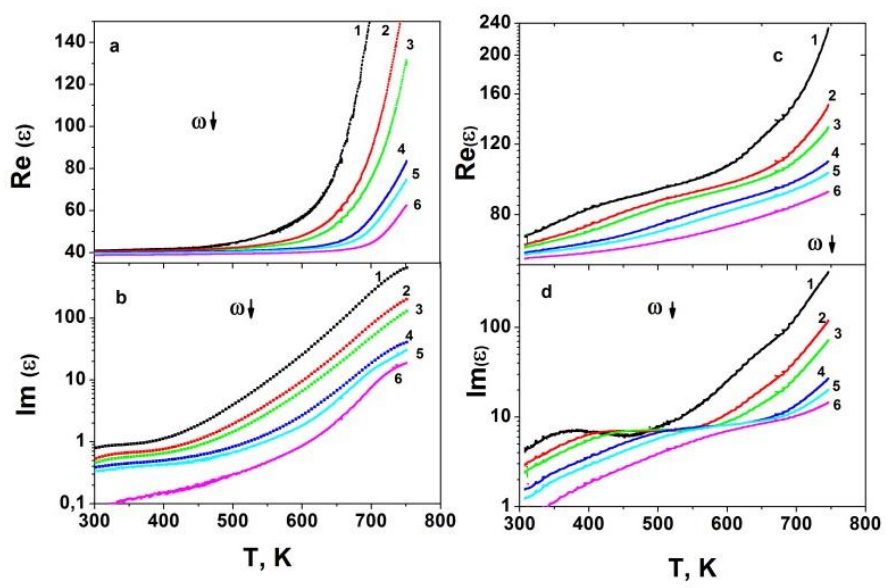

Figure 3 Temperature dependence of the permittivity of $\mathrm{Bi}_{2}\left(\mathrm{Sn}_{1-\mathrm{x}} \mathrm{Cr}_{\mathrm{x}}\right)_{2} \mathrm{O}_{7}, \mathrm{x}=0.05$ and 0.1 at different frequencies: (a) real part and (b) imaginary part of $\mathrm{Bi}_{2}\left(\mathrm{Sn}_{0.95} \mathrm{Cr}_{0.05}\right)_{2} \mathrm{O}_{7}$, (c) real part and (d) imaginary part of $\mathrm{Bi}_{2}\left(\mathrm{Sn}_{0.9} \mathrm{Cr}_{0.1}\right)_{2} \mathrm{O}_{7}$. Curve 1 corresponds to $1 \mathrm{kHz}, 2-5 \mathrm{kHz}, 3-10 \mathrm{kHz}, 4$ $50 \mathrm{kHz}, 5-100 \mathrm{kHz}, 6-300 \mathrm{kHz}$.

One of the criteria for the transition of a system to the dipole glass state is a specific dependence of the dispersion of the real $(\operatorname{Re}(\varepsilon))$ and imaginary $(\operatorname{Im}(\varepsilon))$ parts of the complex permittivity on the frequency near the temperature of the transition to the glass phase. Figure 4 shows the frequency dependence of the permittivity for $\mathrm{Bi}_{2}\left(\mathrm{Sn}_{1-\mathrm{x}} \mathrm{Cr}_{\mathrm{x}}\right)_{2} \mathrm{O}_{7}(\mathrm{x}=0.05$ and 0.1$)$. In the composition with $\mathrm{x}=0.05$, dipole clusters with a short-range order with the thermodynamic mean zero dipole moment $\langle\mathrm{pi}\rangle=0$ are formed. The effect of short-range order can be observed as a change in the frequency dependence of the complex permittivity, which can be 
approximated by the power function $\varepsilon=\mathrm{A} / \omega^{\mathrm{n}}$ at frequencies of up to $105 \mathrm{~Hz}$; at the higher frequencies, the permittivity decreases sharper. The dispersion of the real part of the permittivity in the monoclinic phase is no larger than $10 \%$ and the dielectric loss decreases manifold. At the transition to the trigonal phase, the dispersion increases and the exponent grows from $n=0.05$ to 0.4 . For the composition with $\mathrm{x}=0.1$, the real and imaginary parts of the permittivity have a broad maximum, which shifts toward higher frequencies with increasing temperature. The $\varepsilon(\omega)$ dependences cannot be described within the Debye and Cole-Cole models. Along with the unlimitedly large relaxation times in glasses, the system has a large set of finite relaxation times, i.e., a broad spectrum of relaxation times. In bismuth pyrostannates, the relaxation time spectrum is caused by ion- and electron-relaxation polarization. The change in the relaxation mechanism is observed in the vicinity of $100 \mathrm{kHz}$. Below $100 \mathrm{kHz}$ polarization is due to electron migration and relaxation is associated by electron-phonon interaction. Above $100 \mathrm{kHz}$ relaxation of polarization is due to phonons. For the composition with $\mathrm{x}=0.1$, the dipole glass property were found.
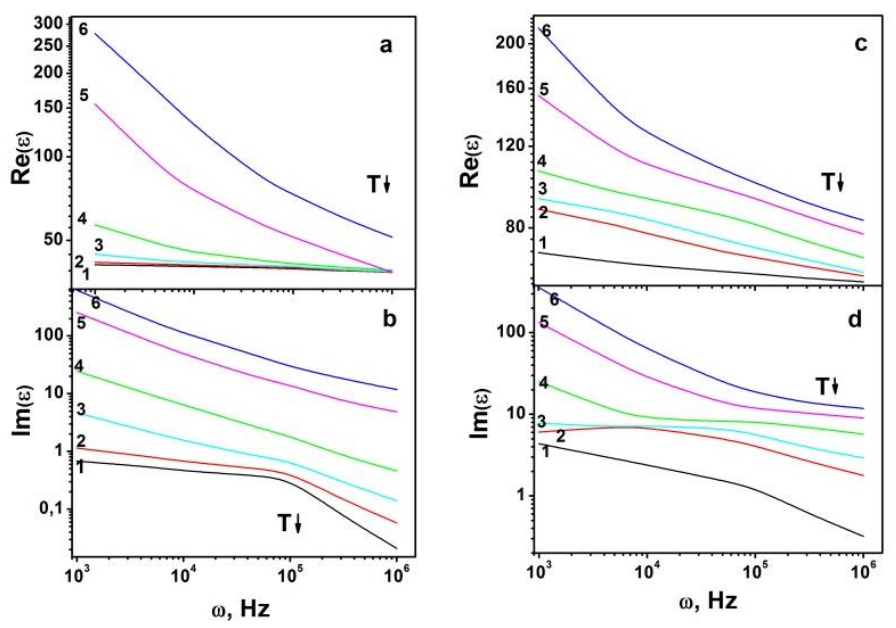

Figure 4 Frequency dependence of the permittivity of $\mathrm{Bi}_{2}\left(\mathrm{Sn}_{1-\mathrm{x}} \mathrm{Cr}_{\mathrm{x}}\right)_{2} \mathrm{O}_{7}, \mathrm{x}=0.05$ and 0.1 at fixed temperatures: (a) real part and (b) imaginary part of $\mathrm{Bi}_{2}\left(\mathrm{Sn}_{0.95} \mathrm{Cr}_{0.05}\right)_{2} \mathrm{O}_{7}$, (c) real part and (d) imaginary part of $\mathrm{Bi}_{2}\left(\mathrm{Sn}_{0.9} \mathrm{Cr}_{0.1}\right)_{2} \mathrm{O}_{7}$. Curve 1 corresponds to $300 \mathrm{~K}$; 2- $400 \mathrm{~K}, 3-500 \mathrm{~K}, 4-600$ K, 5- $700 \mathrm{~K}, 6-750 \mathrm{~K}$

Above $600 \mathrm{~K}$, the imaginary part of the permittivity is well-described by the dependence $\ln (\operatorname{Im}(\varepsilon))=\mathrm{A}-\Delta \mathrm{E} / \mathrm{T}$ with the activation energy, which is almost independent of frequency and concentration and amounts to $\Delta \mathrm{E}=0.82(2) \mathrm{eV}$. The contribution of carriers to the dielectric loss can be ignored, since the relation $\omega \operatorname{Im}(\varepsilon)=\sigma$ is not satisfied. For the composition with $\mathrm{x}=0.05$, the dc temperature behavior of the conductivity and $\operatorname{Im}(\varepsilon)(\mathrm{T})$ are qualitatively different. This allows us to conclude that the dielectric loss and permittivity growth are caused by the ion subsystem and result from the high mobility of bismuth ions in the pyrostannate structure in the region of the $\beta-\gamma$ transition.

\subsection{Raman scattering spectra}

The absence of symmetry center in the $\alpha$ - phase is also confirmed by the presence of Raman spectra. Figure 5 shows room-temperature Raman spectroscopy data for $\mathrm{Bi}_{2}\left(\mathrm{Sn}_{1-\mathrm{x}} \mathrm{Cr}_{\mathrm{x}}\right)_{2} \mathrm{O}_{7}$ ( $x=0$ and 0.1 ) in the frequency range of $100-1000 \mathrm{~cm}^{-1}$. The $\mathrm{Bi}_{2} \mathrm{Sn}_{2} \mathrm{O}_{7}$ spectrum includes a series of broad bands and is consistent with the spectrum data [23]. 
The ideal $\mathrm{A}_{2} \mathrm{~B}_{2} \mathrm{O}(1)_{6} \mathrm{O}(2)$ pyrochlore structure (sp. gr. $F d \overline{3} m$ ) has several types of oscillations: $\Gamma_{R}=A_{l g}+E_{g}+4 F_{2 g}$ [24]. In this representation, there are six main active Raman modes. The spectra shown in Fig. 5 have a number of spectral lines different from the ideal pyrochlore structure, which results from the symmetry lowering (Tab.2). Bismuth pyrostannate with the symmetry $P c\left(C_{S}^{2}\right)$ has a great number of active modes $\Gamma_{R}=526 \mathrm{~A}^{\prime}+527 \mathrm{~A}^{\prime}$. Thus, in the ideal pyrochlore structure, vibrations are not observed below $200 \mathrm{~cm}^{-1}$; in particular, for $\mathrm{Bi}_{\mathrm{x}} \mathrm{Y}_{2-}$ ${ }_{x} \mathrm{Ti}_{2} \mathrm{O}_{7}$ [25], the low-frequency mode corresponds to $226 \mathrm{~cm}^{-1}$. All phonon vibrations of the ideal pyrochlore structure are resolved in a polar monoclinic low-symmetry structure. In the frequency range of $100-200 \mathrm{~cm}^{-1}$, for $\mathrm{Bi}_{2}\left(\mathrm{Sn}_{1-\mathrm{x}} \mathrm{Cr}_{\mathrm{x}}\right)_{2} \mathrm{O}_{7}(\mathrm{x}=0)$, the bending $\left(F_{1 u}\right) \mathrm{O}-\mathrm{Bi}-\mathrm{O}\left(148 \mathrm{~cm}^{-1}\right)$ and stretching $\left(F_{1 u}\right) \mathrm{Bi}-\mathrm{SnO}_{6}\left(188 \mathrm{~cm}^{-1}\right)$ vibrations are active.

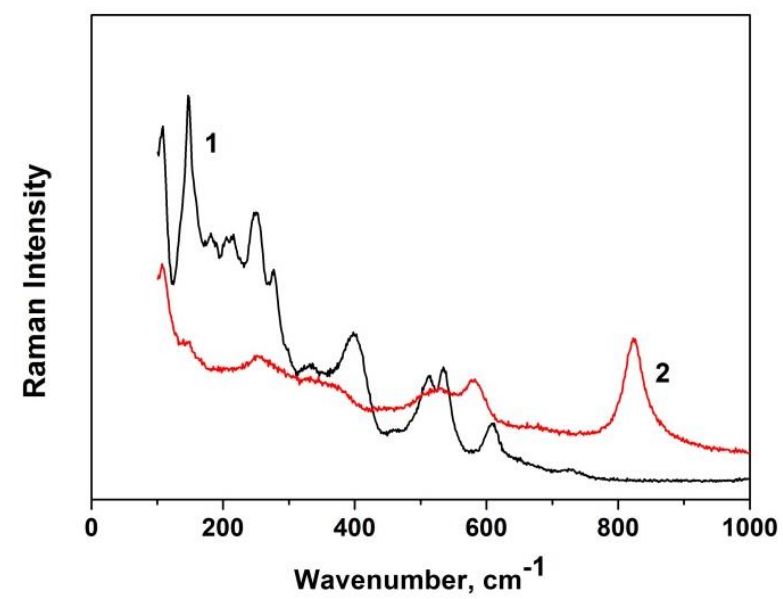

Figure 5 Raman spectrum: curve 1 corresponds to $\mathrm{Bi}_{2} \mathrm{Sn}_{2} \mathrm{O}_{7}, 2-\mathrm{Bi}_{2}\left(\mathrm{Sn}_{0.9} \mathrm{Cr}_{0.1}\right)_{2} \mathrm{O}_{7}$

In the intermediate spectral range of $200-400 \mathrm{~cm}^{-1}$ of $\mathrm{Bi}_{2} \mathrm{Sn}_{2} \mathrm{O}_{7}$, some modes correspond to the active IR spectroscopy vibrations for low-symmetry pyrochlores [26]. The $211 \mathrm{~cm}^{-1}$ spectral line is mainly described by the stretching vibrations $\left(F_{1 u}\right)$ along the $\mathrm{Bi}-\mathrm{SnO}_{6}$ bond. The vibrations with frequencies of $274 \mathrm{~cm}^{-1}$ and $382 \mathrm{~cm}^{-1}$ are defined as bending $\left(F_{1 u}\right) \mathrm{O}-\mathrm{Sn}-\mathrm{O}$ and stretching $\left(F_{1 u}\right) \mathrm{Bi}-\mathrm{O}$. In this range, there are two modes that correspond to the ideal pyrochlore structure, $225\left(F_{2 g}\right)$ and $248 \mathrm{~cm}^{-1}\left(E_{g}\right)$. Mode $\left(F_{2 g}\right)$ is attributed to the displacement of oxygen $\mathrm{O} 1$ in the $\mathrm{SnO}_{6}$ polyhedron [23]. Above $400 \mathrm{~cm}^{-1}$, four groups of vibrations are observed in the $\mathrm{Bi}_{2} \mathrm{Sn}_{2} \mathrm{O}_{7}$ Raman spectrum. The vibrations with $535 \mathrm{~cm}^{-1}$ and $400 \mathrm{~cm}^{-1}$ are classified as bending $\mathrm{O}-\mathrm{Sn}-\mathrm{O}\left(A_{1 g}\right)$ and $\mathrm{Sn}-\mathrm{O}\left(F_{2 g}\right)[27,28]$.

Substitution tin ions by chromium decreased the number and intensity of Raman spectral lines and led to the occurrence of two new modes at frequencies of $581 \mathrm{~cm}^{-1}$ and $822 \mathrm{~cm}^{-1}$. The $581 \mathrm{~cm}^{-1}$ spectral line exists in the optical spectra of compounds with an ideal pyrochlore structure and corresponds to the stretching vibrations of the $\mathrm{Bi}-\mathrm{O}$ bond. The $822 \mathrm{~cm}^{-1}$ highfrequency spectral line cannot be unambiguously interpreted and is defined as an overtone, combination band, or mode $\left(F_{2 g}\right)$ [27].

Table 2. Parameters of phonon modes of the Raman spectra of $\mathrm{Bi}_{2}\left(\mathrm{Sn}_{1-\mathrm{x}} \mathrm{Cr}_{\mathrm{x}}\right)_{2} \mathrm{O}_{7}(\mathrm{x}=0$ and 0.1$)$

\begin{tabular}{|c|c|c|}
\hline $\mathrm{Bi}_{2} \mathrm{Sn}_{2} \mathrm{O}_{7}$ & $\mathrm{Bi}_{2} \mathrm{Sn}_{1.9} \mathrm{Cr}_{0.1} \mathrm{O}_{7}\left(\mathrm{~cm}^{-1}\right)$ & Assignment \\
\hline 108 & 108 & $A_{2 u}$ \\
\hline 148 & 144 broad & O-Bi-O bending $\left(F_{1 u}\right)$ \\
\hline 181 & & Bi-SnO $_{6}\left(F_{1 u}\right)$ \\
\hline
\end{tabular}




\begin{tabular}{|c|c|c|}
\hline 208 & & $\left(F_{1 u}\right)$ \\
\hline 215 & & $\left(F_{2 g}\right)$ \\
\hline 225 & 251 & $\left(E_{g}\right)$ \\
\hline 248 & & O-Sn-O $\left(F_{1 u}\right)$ \\
\hline 274 & & $\left(F_{1 u}\right)$ \\
\hline 332 broad & $\begin{array}{c}\text { O motion in SnO' } \text { polyhedra } \\
\left(F_{2 g}\right)\end{array}$ \\
\hline 400 & & $\begin{array}{c}\text { stretching SnO }{ }_{6} \text { octahedra } \\
\left(A_{1 g}\right)\end{array}$ \\
\hline 512 & & ${\text { O'-vacancy stretching }\left(A_{1 g}\right)}^{\prime}$ \\
\hline 534 & 523 & $\left(F_{2 g}\right)$ stretching Bi-O \\
\hline 608 & & $\left(F_{2 g}\right)$ \\
\hline & 822 & Overtone or combination \\
\hline
\end{tabular}

Substitution of tin ions by $\mathrm{Cr}^{+3}$ does not change the spatial symmetry group and leads to the absence of some spectral lines in the $\mathrm{Bi}_{2} \mathrm{Sn}_{1.9} \mathrm{Cr}_{0.1} \mathrm{O}_{7}$ spectrum in comparison with the $\mathrm{Bi}_{2} \mathrm{Sn}_{2} \mathrm{O}_{7}$ spectrum. This is apparently due to an increase in the local symmetry of bismuth pyrostannate with the disordered $\mathrm{Cr}^{+3}$ ions.

\subsection{Polarization and thermopower}

Figures 6 and 7 present field dependences of the polarization for $\mathrm{Bi}_{2}\left(\mathrm{Sn}_{1-\mathrm{x}} \mathrm{Cr}_{\mathrm{x}}\right)_{2} \mathrm{O}_{7}(\mathrm{x}=$ 0.05 and 0.1 ). For both compositions, the polarization linearly increases with the field and a slight hysteresis is observed in the monoclinic phase. Upon multiple cycling, the hysteresis width increases linearly with the number of cycles for composition with $x=0.05$ (Fig. 6b). In addition, the hysteresis width increases with the quasi-static field amplitude (Fig. 6a). The dielectric susceptibility $\chi=\mathrm{P} / \varepsilon_{0} \mathrm{E}$ determined in an electric field of $800 \mathrm{~V} / \mathrm{cm}$, increases upon heating in the monoclinic phase and reveals a maximum near the temperature of the transition to the dipole glass state (inset in Fig. 7a). Glasses are characterized by a broad susceptibility maximum in the region of dipole moment freezing and irreversible susceptibility behavior upon heating and cooling in an electric field.


Figure 6 Dependence of the polarization of $\mathrm{Bi}_{2}\left(\mathrm{Sn}_{0.95} \mathrm{Cr}_{0.05}\right)_{2} \mathrm{O}_{7}$ versus electric field (a) at frequency $0.01 \mathrm{~Hz}$ and different voltage at $300 \mathrm{~K}$ : curve 1 corresponds to $10 \mathrm{~V}, 2-50 \mathrm{~V}, 3-150$ $\mathrm{V}, 4-200 \mathrm{~V}$, (b) Ten cycles of polarization at $300 \mathrm{~K}$, the tenth - a thick line, (c) Ten cycles of 
polarization at $450 \mathrm{~K}$, the tenth - a thick line, (d) Width of a hysteresis of polarization, curve 1 corresponds to $\mathrm{Bi}_{2}\left(\mathrm{Sn}_{0.95} \mathrm{Cr}_{0.05}\right)_{2} \mathrm{O}_{7}, 2-\mathrm{Bi}_{2}\left(\mathrm{Sn}_{0.9} \mathrm{Cr}_{0.1}\right)_{2} \mathrm{O}_{7}$

Bismuth pyrostannates are polymorphic and characterized by the coexistence of monoclinic and trigonal phases above the $\alpha-\beta$ structural transition. Delocalization of holes in the vicinity of chromium ions leads to diffusion and accumulation of charge in traps at the intercrystalline domain walls. Under the action of an external electric field, carriers diffuse to the domain surface and are localized in traps. As a result, the intercrystalline boundaries are charged, which leads to broadening of the hysteresis loop. There exist several models explaining the hysteresis loop growth. The most wide-spread models for bulk systems (crystals) are domain pinning on the space charges accumulated on domain walls, pinning on the formed defective clusters, and formation of dipole defects affecting the polarization [29-31]. The formation of charged boundary and partial shielding leads to the non-uniform distribution of potential in the sample volume. As a result of crystal structure rearrangement, the defect density changes; in particular, the oxygen vacancy concentration drops [32].
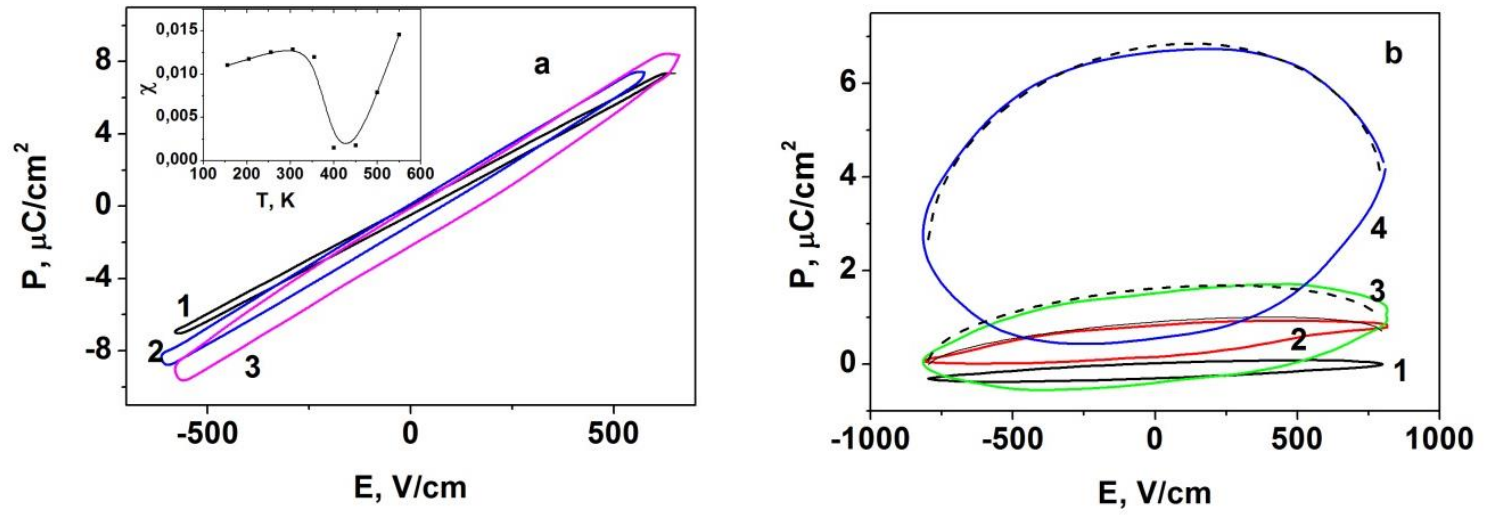

Figure 7 Dependence of the polarization of $\mathrm{Bi}_{2}\left(\mathrm{Sn}_{0.9} \mathrm{Cr}_{0.1}\right)_{2} \mathrm{O}_{7}$, versus electric field at frequency $0.01 \mathrm{~Hz}$ and different temperatures: (a) Curve 1 corresponds to $155 \mathrm{~K}, 2-300 \mathrm{~K}, 3-350 \mathrm{~K}$, (b)

Curve 1 corresponds to $400 \mathrm{~K}$ and silver contacts, 2-400 K and, 3- $450 \mathrm{~K}, 4-500 \mathrm{~K}, 2$, 3, 4contacts varnished. Insert- the temperature dependence of susceptibility. Dash curves correspond to theoretical calculations

In the $\beta$ phase, the electron-relaxation polarization prevails. This type of polarization is typical of solid dielectrics with defects or impurity ions, which can trap electrons. In zero electric field, the trapped electrons can pass from one probable position to another under the action of thermal fluctuations. In an external electric field, such transitions will mainly occur in the field direction and the electric dipole moment will be induced in the bulk of a dielectric; i.e., the polarization will be observed. The time of polarization relaxation at room temperature is $\left(10^{-2}-\right.$ $10^{-6}$ ) s. The most probable electron polarization mechanism is related to the occurrence of anion vacancies upon non-isovalent substitution of tin for chromium ions. Oxygen vacancies are equivalent to positive charges, near which, to compensate them in accordance with the electroneutrality principle, quasi-free electrons are localized, which determine the heat electron polarization.

As the number of cycles increases, the hysteresis width in the $\beta$ - phase decreases and the hysteresis shifts along the polarization axis with a slight increase in the space charge in zero fields (Fig. 6b). 
We calculate the hysteresis and induced polarization using the following model. At the domain surface, there are traps (vacant surface states). In an external electric field, electrons from the impurity (defect) states in the bulk move to the surface states, where the electric charge $\mathrm{Q}=\mathrm{eN}$ is accumulated ( $\mathrm{N}$ is the number of electrons passed from the bulk). The sample polarization is caused by the charges localized on the surface with charge density $\sigma_{0}$ and in the bulk $\mathrm{P}=\varepsilon_{0} \chi \mathrm{E}$ and migration of weakly bound electrons inside grains:

$$
P=\int j d t=\int\left(\delta_{0} E\right) d t=\int(e n \mu E) d t=\int\left(e n \mu E_{0} \sin (\omega t)\right) d t=e n \mu \sqrt{E_{0}^{2}-E^{2}} / \omega,(1)
$$

where $\mu$ is the carrier mobility and $\mathrm{n}$ is the free carrier density. The hysteresis width $\Delta \mathrm{P}=2 \mathrm{en} \mu \mathrm{E}_{0}$ is determined by the concentration of current carriers, mobility and external electric field amplitude. The resulting polarization is

$$
P=\frac{e n \mu \sqrt{E_{0}^{2}-E^{2}}}{\omega}+\sigma_{0} \varepsilon_{0} E
$$

The calculated polarization values are in good agreement with the experimental data. As the number of cycles of the quasi-static field increases, the impurity electron density and oxygen defect concentration in the bulk decrease; the charge on the crystallite surface $\sigma_{0}$ and static dielectric susceptibility increase, it leads to an increase in polarization.

The effect of surface states can be determined by comparing the polarization of the samples with silver contacts and dielectric lacquer layer. The contribution of homo-charges at the dielectric surface, which passed from the metal electrode to the surface bismuth pyrostannate layers, to the polarization will decrease. However, the polarization and hysteresis increase by $50-80 \%$ as compared with the sample with the deposited electrode. This is due to a decrease in leakage currents. The electron density at the domain walls grows.

The mechanism of relaxation of polarization and functional dependence of the polarization from time will be determined for a switched-on and off electric field in the form of a rectangular pulse with frequencies of $0.1,0.01,0.003$, and $0.001 \mathrm{~Hz}$. Figure 8 shows time dependences of polarization in the monoclinic and trigonal phases. In the $\alpha$ - phase, the polarization sharply increases for $\mathrm{x}=0.05$ upon switching-on the electric field and is directly proportional to it. For the composition with $\mathrm{x}=0.1$, upon switching-on the electric field, the polarization in the $\alpha$ - phase increases according to the power law $\mathrm{P}=\mathrm{At}^{\mathrm{n}}$, where the exponent increases with temperature from $n=0.7$ to 1 in the $\beta$ - phase. As the electric field amplitude decreases, the polarization grows slower. In the dipole glass state, after switching-off the electric field, the polarization relaxes according to the logarithmic law $P=P_{0}-\gamma \ln t$ at $t>(20-40) \mathrm{s}$. In the $\beta$ - phase, after switching-off the electric field, the polarization remains almost invariable and depends on the electric field amplitude. Upon cooling from $420 \mathrm{~K}$ to room temperature in zero electric field, the sample is not polarized. Cooling of the sample to $300 \mathrm{~K}$ for $10 \mathrm{~min}$ in a field of $800 \mathrm{~V} / \mathrm{cm}$ followed by contact short-circuiting for $15 \mathrm{~min}$ yields a residual polarization of 0.1 $\mu \mathrm{C} / \mathrm{cm} 2$, which remains stable for several hours. 

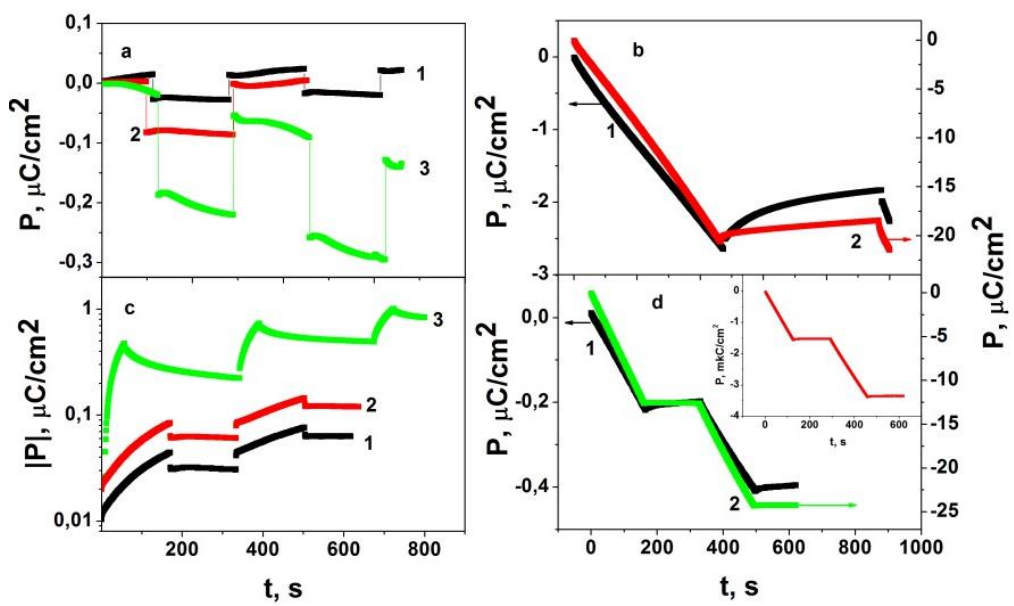

Figure 8 Dependence of the polarization versus time: (a) $\mathrm{Bi}_{2}\left(\mathrm{Sn}_{0.95} \mathrm{Cr}_{0.05}\right)_{2} \mathrm{O}_{7}$ at temperature $300 \mathrm{~K}$, frequency $0.003 \mathrm{~Hz}$ and different voltage, curve 1 corresponds to $50 \mathrm{~V}$, 2$100 \mathrm{~V}, 3-200 \mathrm{~V}$. (b) $\mathrm{Bi}_{2}\left(\mathrm{Sn}_{0.95} \mathrm{Cr}_{0.05}\right)_{2} \mathrm{O}_{7}$ at frequency $0.001 \mathrm{~Hz}$ and different temperatures, 1-360 $\mathrm{K}, 2-400 \mathrm{~K}$. (c) $\mathrm{Bi}_{2}\left(\mathrm{Sn}_{0.9} \mathrm{Cr}_{0.1}\right)_{2} \mathrm{O}_{7}$ at temperature $300 \mathrm{~K}$, frequency $0.003 \mathrm{~Hz}$ and different voltage, curve 1 corresponds to $50 \mathrm{~V}, 2-100 \mathrm{~V}, 3-200 \mathrm{~V}$. (d) Bi2(Sn0.9Cr0.1)2O7 at $400 \mathrm{~K}$, frequency $0.003 \mathrm{~Hz}$ and different voltage, $1-10 \mathrm{~V}, 2-200 \mathrm{~V}$, insert-50 V

The electrical resistance in the monoclinic phase upon heating above room temperature increases by 15-30\% and slightly changes upon temperature variation in the trigonal phase for $\mathrm{x}$ $=0.05$ (Fig. 9). In bismuth pyrostannate with $\mathrm{x}=0.1$, the resistance maximum in the region of transition to the dipole glass state was found. The conductivity of $\mathrm{Bi}_{2}\left(\mathrm{Sn}_{1-\mathrm{x}} \mathrm{Cr}_{\mathrm{x}}\right)_{2} \mathrm{O}_{7}$ solid solutions is due to impurity states $\sigma=q \mu \mathrm{n}$, where $\mathrm{n}$ is the concentration of current carriers, practically independent of temperature. The temperature dependence of the resistance is mainly due to the mobility of the current carriers and is aroused to scattering by charged impurities. For a composition with $\mathrm{x}=0.1$, a correlated state of dipoles and a potential is formed in the region of transition to the dipole glass state. The scattering of current carriers by fluctuations of this potential leads to a maximum of electrical resistance._The carrier type can be determined from the thermopower.

Figure 10 shows the temperature dependence of the thermopower with the change in the sign in the range of 430-550 K. Upon heating, the thermopower sign changes from positive to negative at $\mathrm{T}=555 \mathrm{~K}$ for $\mathrm{x}=0.05$. As the concentration increases, the thermopower sign change shifts to the dipole glass region, where the electrical resistance is maximum. In the monoclinic phase, there is a hole type of current carriers induced by chromium ions. In the trigonal phase, the electronic type of current carriers for oxygen vacancies prevails. 


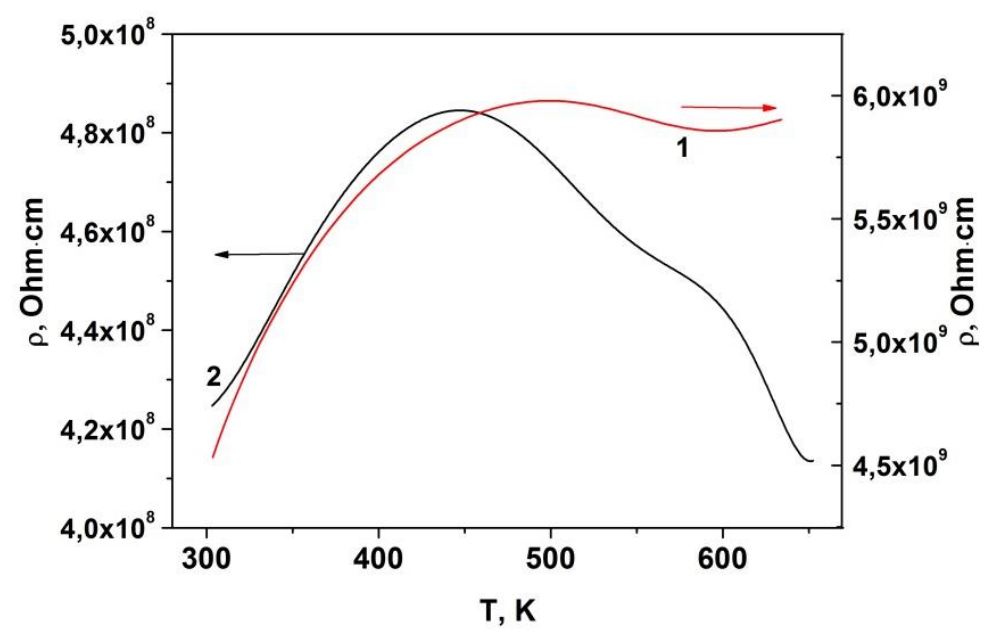

Figure 9 Temperature dependence of electrical resistance versus temperature, curve 1 corresponds to $\mathrm{Bi}_{2}\left(\mathrm{Sn}_{0.95} \mathrm{Cr}_{0.05}\right)_{2} \mathrm{O}_{7}, 2-\mathrm{Bi}_{2}\left(\mathrm{Sn}_{0.9} \mathrm{Cr}_{0.1}\right)_{2} \mathrm{O}_{7}$

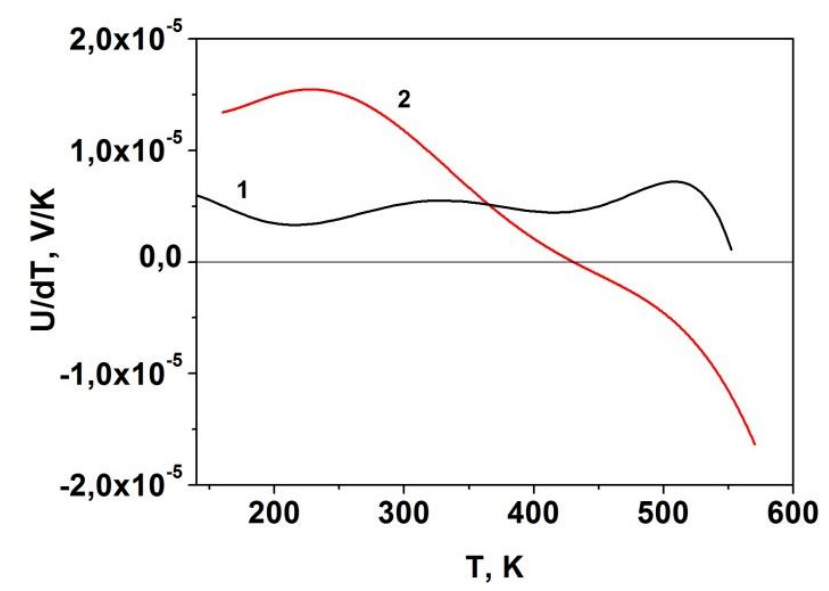

Figure 10 Temperature dependence of the thermopower coefficient: curve 1 corresponds to $\mathrm{Bi}_{2}\left(\mathrm{Sn}_{0.95} \mathrm{Cr}_{0.05}\right)_{2} \mathrm{O}_{7}, 2-\mathrm{Bi}_{2}\left(\mathrm{Sn}_{0.9} \mathrm{Cr}_{0.1}\right)_{2} \mathrm{O}_{7}$

\subsection{Model}

In the monoclinic phase, non-isovalent substitution of tin for chromium leads to the displacement of bismuth ions toward chromium with the formation of a dipole moment. At low concentrations, the short-range order forms, the effect of which manifests itself in the highfrequency dielectric loss. With increasing concentration, degenerate states arise in the dipole moment direction. For example, in the $\mathrm{Bi}^{+3}$ environment there are two $\mathrm{Cr}^{+3}$ ions with a twofold degeneracy in the displacement of bismuth ions, which can be described by two potential wells with the characteristics dependent on the nearest environment. For the composition with $\mathrm{x}=0.1$, there is the distribution of potential barriers and relaxation times.

The Debye and Cole-Cole models are based on the exponential dependence of the polarization relaxation. The frequency and temperature dependences of the permittivity cannot be described in the framework of these models, which indicates the nonexponential relaxation behavior. The experimental data are described by the model of the heterogeneous distribution of domains, which have the exponentially relaxation with account for the dynamical correlations. The size distribution of domains obeys the Poisson's distribution with the relaxation rate 
$\omega_{s} \propto \exp \left(-\left(\delta E_{S}\right) /\left(2 k_{B} T\right)\right)$, where the distance between the energy levels is inversely proportional to the linear domain size $\delta E_{S} \propto 1 / s$. The relaxation rate can be expressed as $\omega_{s}=\omega_{0} \exp ((-C) / s)$ ), where $\mathrm{C}$ is the dynamic correlation parameter. The time dependence of polarization is [33]:

$$
P(t)=P_{0} \int_{0}^{\infty} d s s^{10 / 9} \exp \left(-s^{2 / 3}\right) \exp \left[-t \omega_{0} \exp (-C / s)\right]
$$

In the limit cases, at $\mathrm{C}<0$ the polarization exponentially depends on time and, at the positive dynamic correlations $\mathrm{C}>0$, turns to the power function. As the temperature increases, the dynamic correlation parameter decreases and the temperature of the maximum dielectric loss shifts toward higher frequencies with the sharper dielectric loss drop. In the dipole glass state, when the electric field is switched on, the polarization increases as $\mathrm{P}(\mathrm{t})=(\mathrm{t} / \tau)^{\delta} \exp (-\mathrm{t} / \tau)$ with $\delta=$ $1 / 3$. When the dc electric field is switched off, the relaxation $P(t)$ is described by the function $\mathrm{P}(\mathrm{t})=\mathrm{P}_{0}\left(1-(\mathrm{t} / \tau)^{\delta}\right)$, where the relaxation time $\tau$ depends on the prehistory and decreases with increasing cycle number. The relaxation crossover from the power to logarithmic function occurs in the range of $\mathrm{t}=(20-40) \mathrm{s}$.

The transition from the monoclinic to trigonal phase is polymorphic with the two coexisting phases and crystalline interfaces. In the trigonal phase, the energy of binding of a hole with the chromium ion decreases; holes delocalize and participate in the Brownian motion. In an external electric field, diffusion occurs mainly in the field direction. Holes are localized in the traps on domain walls, the charge of which is partially compensated by electrons from oxygen vacancies. The charge distribution in the sample is schematically illustrated in Fig. 11. Electrons are related to oxygen vacancies, the activation energy of which is higher than the activation energy of holes. The charged interphase boundary induce the space charge proportional to

$$
Q=e N_{C r} \exp \left(-\frac{\Delta E_{1}}{k T}\right)-e N_{0} \exp \left(\frac{\Delta E_{2}}{k T}\right)-\int I_{r} d t
$$

where $N_{C r}$ and $N_{O}$ are the chromium ion and oxygen vacancy concentrations, $\Delta E_{1}$ and $\Delta E_{2}$ are the hole and electron activation energies, and $I_{r}$ is the current of charge leakage to the contacts.
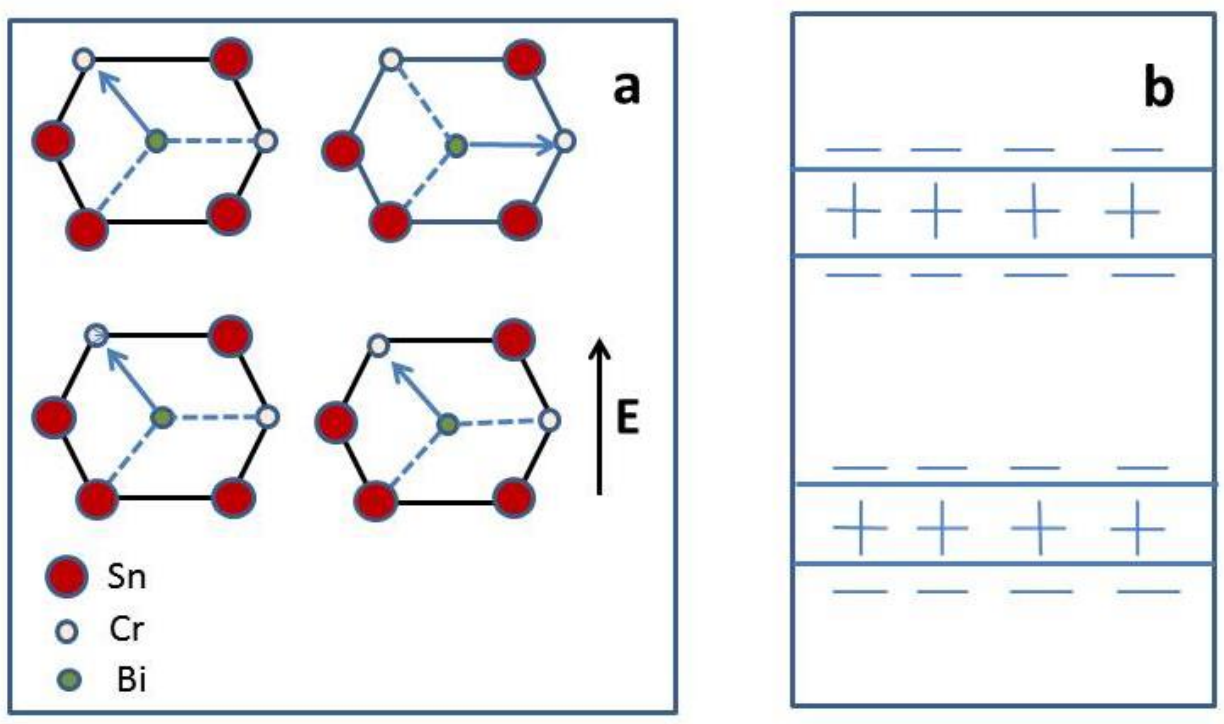

Figure 11 Scheme of distribution of charges in $\mathrm{Bi}_{2}\left(\mathrm{Sn}_{1-\mathrm{x}} \mathrm{Cr}_{\mathrm{x}}\right)_{2} \mathrm{O}_{7}, \mathrm{x}=0.05,0.1$. (a) Distribution of dipole moments, (b) distribution of charges on interphase borders.

\section{Conclusions}


The dipole glass state in bismuth pyrostannate $(\mathrm{x}=0.1)$ with a monoclinic structure was determined from the frequency and temperature dependences of the permittivity. The relaxation of polarization is described by the power and logarithmic dependence. The dielectric susceptibility maximum in a dc electric field was found. In the vicinity of the dipole moment freezing point in $\mathrm{Bi}_{2}\left(\mathrm{Sn}_{0.9} \mathrm{Cr}_{0.1}\right)_{2} \mathrm{O}_{7}$, the electrical resistance maximum and change of sign of thermopower were established. The absence of inversion center in doped bismuth stannates was confirmed by the Raman spectroscopy investigations.

In the $\beta$ - phase, the hysteresis of polarization shifted along the polarization axis was found. The hysteresis width was shown to increase upon heating. In the trigonal phase, the thermopower changes its sign from positive to negative upon heating, which is indicative of the existence of two charge carrier types.

The localization of holes in the $\alpha$-phase in the vicinity of chromium ions leads to the shift of bismuth ions with the formation of dipole moments. Above the temperature of the $\alpha-\beta$ structural transition, there are domains of both phases. The diffusion of holes and oxygen vacancies and their pinning on the intercrystalline domain walls lead to the charge accumulation (shift along the polarization axis). Partial shielding of the charged boundary by electrons and their diffusion in an external electric field cause the polarization hysteresis.

\section{Acknowledgments}

This study was supported by the Russian Foundation for Basic Research project N 18-5200009 Bel_a, № 18-32-00079 mol_a, the state order № 3.5743.2017/6.7.

\section{Conflicts of interest}

There are no conflicts to declare.

\section{References:}

[1] Jo W, Cho H-J, Noh T W, Kim B I, Kim D-Y, Khim Z G, Kwun S I 1993 Structural and electro-optic properties of pulsed laser deposited $\mathrm{Bi}_{4} \mathrm{Ti}_{3} \mathrm{O}_{12}$ thin films on $\mathrm{MgO}$ Appl. Phys. Lett. $632198-2200$

[2] Higuchi T, Nakamura M, Hachisu Y, Saitoh M, Hattori T, Tsukamoto T 2004 Ferroelectric properties of $\mathrm{Bi}_{4} \mathrm{Ti}_{3} \mathrm{O}_{12}$ thin films prepared on $\mathrm{TiO}_{2}$ anatase layer Jpn. J. Appl. Phys. 43 65856585

[3] Kagata H, Kato J, Inoue T, Kameyama I 1992 Low-fire bismuth-based dielectric ceramics for microwave use Jpn. J. Appl Phys. 31 3152-3155, doi: 10.1143/JJAP.31.3152

[4] Salamat A, Hector A L, McMillan P F, and Ritter C 2011 Bonding and phase relations in $\mathrm{Bi}_{2} \mathrm{Sn}_{2} \mathrm{O}_{7}$ and $\mathrm{Bi}_{2} \mathrm{Ti}_{2} \mathrm{O}_{7}$ pyrochlores: new insights from high pressure and high temperature studies Inorg. Chem. 50 11905-11913, dx.doi.org/10.1021/ic200841v

[5] Hector A L, Wiggin S B 2004 Synthesis and structural study of stoichiometric $\mathrm{Bi}_{2} \mathrm{Ti}_{2} \mathrm{O}_{7}$ pyrochlore J. Solid State Chem. 177 139-145

[6] Hill N A 2002 Density functional studies of multiferroic magnetoelectrics Annu. Rev. Mater. Res. 32 1-9

[7] Applegate R, Hayre N R, Singh R R P, Lin T, Day A G R, and Gingras M J P 2012 Vindication of $\mathrm{Yb}_{2} \mathrm{Ti}_{2} \mathrm{O}_{7}$ as a model exchange quantum spin ice Phys. Rev. Lett. 109097205

[8] Kadowaki H, Ishii Y, Matsuhira K, and Hinatsu Y 2002 Neutron scattering study of dipolar spin ice $\mathrm{Ho}_{2} \mathrm{Sn}_{2} \mathrm{O}_{7}$ : frustrated pyrochlore magnet Phys. Rev. B 65, 144421 
[9] Benton O, Sikora O, and Shannon N 2012 Seeing the light: Experimental signatures of emergent electromagnetism in a quantum spin ice Phys. Rev. B 86075154

[10] Thompson J D, McClarty P A, Rønnow H M, Regnault L P, Sorge A, and Gingras M J P 2011 Rods of neutron scattering intensity in $\mathrm{Yb}_{2} \mathrm{Ti}_{2} \mathrm{O}_{7}$ : Compelling evidence for significant anisotropic exchange in a magnetic pyrochlore oxide Phys. Rev. Lett. 106187202

[11] Castelnovo C, Moessner R, and Sondhi S L 2008 Magnetic monopoles in spin ice Nature. $45142-5$

[12] Youngblood R, Axe J D, McCoy B M 1980 Correlation in ice-rule ferroelectrics Phys. Rev. B 215212

[13] Kamba S, Porokhonskyy V, Pashkin A, Bovtun V, Petzelt J, Nino J C, Trolier-McKinstry S, Lanagan M T and Randall C A 2002 Anomalous broad dielectric relaxation in $\mathrm{Bi}_{1.5} \mathrm{Zn}_{1.0} \mathrm{Nb}_{1.5} \mathrm{O}_{7}$ pyrochlore Phys. Rev. B 66054106.

[14] Roth R S, Res J 1956 Pyrochlore-type compounds containing double oxides of trivalent and tetravalent ions Nat. Bur. Stand. 56 17-25

[15] Ismunandar, Kennedy B J, Hunter B A, Vogt T 1997 Bonding and structural variations in doped $\mathrm{Bi}_{2} \mathrm{Sn}_{2} \mathrm{O}_{7}$ J. Solid State Chem. 131 317-325

[16] Vetter G, Queyroux F, Gilles C 1978 Preparation, stabilite et etude cristallographique preliminaire du compose $\mathrm{Bi}_{2} \mathrm{Sn}_{2} \mathrm{O}_{7}$ J Mater. Res. Bull. 13 211-216

[17] Evans I R, Howard J A K, Evans J S O $2003 \alpha-\mathrm{Bi}_{2} \mathrm{Sn}_{2} \mathrm{O}_{7}-$ a 176 atom crystal structure from powder diffraction data J. Mater. Chem. 13 2098-2103

[18] Shannon R D, Bierlein J D, Gillson J L, Jones G A, Sleight A W 1980 Polymorphism in $\mathrm{Bi}_{2} \mathrm{Sn}_{2} \mathrm{O}_{7}$ J. Phys. Chem. Solids 41 117-122

[19] Kahlenberg V, Zeiske $\mathrm{T} 1997$ Structure of .GAMMA.- $\mathrm{Bi}_{2} \mathrm{Sn}_{2} \mathrm{O}_{7}$ by high temperature powder neutron diffraction. Z. Kristallogr. 212 297-301

[20] Jones R H, Knight K S 1997 The structure of $\gamma-\mathrm{Bi}_{2} \mathrm{Sn}_{2} \mathrm{O}_{7}$ at $725{ }^{\circ} \mathrm{C}$ by high-resolution neutron diffraction: implicationsfor bismuth(III)-containing pyrochlores J. Chem. Soc. Dalton Trans. 2551-2555

[21] Bruker AXS TOPAS V4: General profile and structure analysis software for powder diffraction data. - User's Manual. Bruker AXS, Karlsruhe, Germany. 2008.

[22] Shannon R D 1976 Revised effective ionic radii and systematic studies of interatomic distances in halides and chalcogenides Acta Cryst. A 32 751-767

[23] Silva R X, Paschoal C W A, Almeida R M, Carvalho Castro M Jr, Ayala A P, Auletta J T, Lufaso M W 2013 Temperature-dependent Raman spectra of $\mathrm{Bi}_{2} \mathrm{Sn}_{2} \mathrm{O}_{7}$ ceramics Vibrational Spectroscopy 64 172-177

[24] Glerup M, Nielsen OF, Poulsen FW 2001 The structural transformation from the pyrochlore structure, $\mathrm{A}_{2} \mathrm{~B}_{2} \mathrm{O}_{7}$, to the fluorite structure, $\mathrm{AO}_{2}$, studied by raman spectroscopy and defect chemistry modeling J. Solid State Chem. 160 25-32

[25] Henderson S J, Shebanova O, Hector A L, McMillan P F, Weller M T, 2007 Structural variations in pyrochlore-structured $\mathrm{Bi}_{2} \mathrm{Hf}_{2} \mathrm{O}_{7}, \mathrm{Bi}_{2} \mathrm{Ti}_{2} \mathrm{O}_{7}$ and $\mathrm{Bi}_{2} \mathrm{Hf}_{2-\mathrm{x}} \mathrm{Ti}_{\mathrm{x}} \mathrm{O}_{7}$ solid solutions as a function of composition and temperature by neutron and X-ray diffraction and raman spectroscopy Chem. Mater. 19 1712-1722

[26] Fischer M, Malcherek T, Bismayer U, Blaha P, Schwarz K, 2008 Structure and stability of $\mathrm{Cd}_{2} \mathrm{Nb}_{2} \mathrm{O}_{7}$ and $\mathrm{Cd}_{2} \mathrm{Ta}_{2} \mathrm{O}_{7}$ explored by ab initio calculations Phys. Rev. B 78014108

[27] Maczka M, Sanjuán M L, Fuentes A F, Macalik L, Hanuza J, Matsuhira K, Hiroi Z 2009

Temperature-dependent studies of the geometrically frustrated pyrochlores $\mathrm{Ho}_{2} \mathrm{Ti}_{2} \mathrm{O}_{7}$ and $\mathrm{Dy}_{2} \mathrm{Ti}_{2} \mathrm{O}_{7}$ Phys. Rev. B 79214437 
[28] Aplesnin S S, Udod L V, Sitnikov M N, Shestakov N P $2016 \mathrm{Bi}_{2}\left(\mathrm{Sn}_{0.95} \mathrm{Cr}_{0.05}\right)_{2} \mathrm{O}_{7}$ : Structure, IR spectra, and dielectric properties Ceramics International 42 5177-5183

[29] Kobune M, Ishito H, Mineshige A, Fujii S, Takayama R, Tomozawa A 1998 Relationship between pyroelectric properties and electrode sizes in $(\mathrm{Pb}, \mathrm{La})(\mathrm{Zr}, \mathrm{Ti}) \mathrm{O}_{3}(\mathrm{PLZT})$ thin films Jpn. J. Appl. Phys. 37 5154-5157

[30] Afanasjev V P, Petrov A A, Pronin I P, Tarakanov E A, Kaptelov E Yu, Graul J 2001 Polarization and self-polarization in thin $\mathrm{PbZr}_{1-\mathrm{x}} \mathrm{Ti}_{\mathrm{x}} \mathrm{O}_{3}$ (PZT) films J. Phys.: Cond. Matter 13 $8755-8763$

[31] Dimos D, Warren W L, Sinclair M B, Tuttle B A, Schwartz R W 1994 Photoinduced hysteresis changes and optical storage in $(\mathrm{Pb}, \mathrm{La})(\mathrm{Zr}, \mathrm{Ti}) \mathrm{O}_{3}$ thin films and ceramics $J$. Appl. Phys. 76 4305-4315

[32] Almeida R M, Paschoal C W A, Auletta J T, Kann Z R, Lufaso M W, 2012 Ionic conductivity in $\mathrm{Bi}_{2} \mathrm{Sn}_{2} \mathrm{O}_{7}$ ceramics Ceramics International 38 1275-1279

[33] Bottcher C J F, Bordewijk P, Theory of Electric Polarization, v. 2: Dielectrics in Time-Dependent Fields, Elsevier, Amsterdam, 1992 